\section{Eight New Somatic Hybrid Citrus Rootstocks with Potential for Improved Disease Resistance}

\author{
Eliezer S. Louzada ${ }^{1}$, Jude W. Grosseti, Frederick G. Gmitter, Jr. ${ }^{2}$, \\ Beatriz Nielsen ${ }^{3}$, and J.L. Chandler ${ }^{3}$ \\ Department of Horticultural Sciences, Citrus Research and Education \\ Center, Institute of Food and Agricultural Sciences, University of \\ Florida, 700 Experiment Station Road, Lake Alfred, FL 33850
}

\author{
Xiu Xin Deng ${ }^{2}$ \\ Department of Horticulture, Huazhong Agricultural University, Wuhan \\ Hubei 430070, People's Republic of China
}

\author{
Nicasio Tusa ${ }^{4}$ \\ Centro di Studio per il Miglioramento Genetico degli Agrumi, Consiglio \\ Nazionale delle Ricerche, Male delle Scienze, Palenno 90128, Sicily
}

Additional index words. citrus blight, citrus breeding, citrus tristeza virus, protoplast fusion, tetraploid, tissue culture, Citrus

\begin{abstract}
Protoplast culture following polyethylene glycol-induced fusion resulted in the regeneration of vigorous tetraploid somatic hybrid plants from eight complementary parental rootstock combinations: Citrus reticulata Blanco (Cleopatra mandarin) $+C$. aurantium L. (sour orange), C. reticulata (Cleopatra mandarin) + C. jambhiri Lush (rough lemon), C. reticulata (Cleopatra mandarin) + C. volkameriana Ten. \& Pasq. (Volkamer lemon), C. reticulata (Cleopatra mandarin) + C. limonia Osb. (Rangpur), C. sinensis (L.) Osb. (Hamlin sweet orange) + C. limonia (Rangpur), C. aurantium (sour orange) $+C$. volkameriana (Volkamer lemon) zygotic seedling, $C$. auruntium hybrid (Smooth Flat Seville) $+C$. jambhiri (rough lemon), and $C$. sinensis (Valencia sweet orange) + Carrizo citrange [C. paradisi Macf. $\times$ Poncirus trifoliata (L.) Raf.]. Diploid plants were regenerated from nonfused callus-derived protoplasts of Valencia sweet orange and Smooth Flat Seville and from nonfused leaf protoplasts of sour orange, Rangpur, rough lemon, and Volkamer lemon. Regenerated plants were classified according to leaf morphology, chromosome number, and leaf isozyme profiles. All somatic hybrid plants were tetraploid $(2 n=4 x=36)$. One autotetraploid plant of the Volkamer lemon zygotic was recovered, apparently resulting from a homokaryotic fusion. These eight new citrus somatic hybrids have been propagated and entered into field trials.
\end{abstract}

Somatic hybridization via protoplast fusion has become a powerful tool in Citrus for combining superior genomes to produce viable allotetraploid plants. New genetic combinations produced by protoplast fusion include interspecific somatic hybrids (Grosser et al.; 1989, 1991; Kobayashi et al., 1988a, 1988b; Ohgawara et al., 1989; Tusa et al., 1990), intergeneric somatic hybrids from sexually compatible parents (Deng et al., 1991; Grosser and Gmitter, 1990a;

\footnotetext{
Received for publication 27 Jan. 1992. Accepted for publication 13 Apr. 1992. Research conducted at the Citrus Research and Education Center, Lake Alfred, Fla. Florida Agricultural Experiment Station Journal Series no. R-02133. We thank S. Huang and X.L. Hu for technical assistance. The cost of publishing this paper was defrayed in part by the payment of page charges. Under postal regulations, this paper therefore must be hereby marked advertisement solely to indicate this fact:

${ }^{1}$ Visiting scientist from the Univ. of Rio de Janeiro, Brazil

${ }^{2}$ Associate Professor.

${ }^{3}$ Biological Scientist.

${ }^{4}$ Researcher.
}

pest resistance into horticulturally desirable rootstocks adapted to the various environmental conditions that exist in Florida.

Rough lemon, Volkamer lemon, and Rangpur have been used as rootstocks, because trees on these stocks are vigorous, highyielding, and tristeza- and drought-tolerant (Castle, 1987; Castle et al., 1989). However, their use has declined because they are highly susceptible to citrus blight. Cleopatra mandarin has become an increasingly important rootstock that is less susceptible to citrus blight than the rootstocks named above, tolerant to tristeza, and cold-hardy. Trees grafted on Cleopatra mandarin are moderately vigorous but are slow to reach full bearing potential (Castle et al., 1989). Sweet orange is tolerant of citrus blight, but is not used as a rootstock due to Phytophthora susceptibility. Somatic hybridization of Cleopatra mandarin with rough lemon, Volkamer lemon, and Rangpur; 'Hamlin' sweet orange with Rangpur; and 'Valencia' sweet orange with Carrizo citrange was attempted to generate vigorous productive rootstocks with acceptable horticultural characteristics but improved blight tolerance.

Sour orange, formerly the most important rootstock in almost every citrus-growing region of the world, is still important in some areas because of its yield potential, favorable influence on fruit quality, wide soil adaptability, and tolerance to cold, Phytophthorainduced diseases, and citrus blight (Castle, 1987; Castle et al., 1989). However, its extreme susceptibility to tristeza-induced decline with sweet orange or grapefruit scions has drastically reduced or eliminated its use in most citrus-growing regions, including Florida and Brazil. Somatic hybridization of sour orange with tristeza-tolerant Cleopatra mandarin and Volkamer lemon, and Smooth Flat Seville with tristeza-tolerant rough lemon was attempted to generate sour orange-type rootstocks that are tolerant to tristeza virus and citrus blight.

Leaf protoplasts of sour orange, rough lemon, Volkamer lemon, and Carrizo citrange were isolated from young nucellar seedlings maintained in a growth chamber (16-h photoperiod, $300 \mu \mathrm{mol} \cdot \mathrm{m}^{-2} \cdot \mathrm{s}^{-1}$ light intensity, 26 to $30 \mathrm{C}$; Grosser and Chandler, 1987). Protoplasts of Cleopatra mandarin, 'Hamlin' and 'Valencia' sweet oranges, sour orange, and Smooth Flat Seville were isolated from friable, nucellus-derived, embryogenic callus cultures maintained on either EME or $\mathrm{H}+\mathrm{H}$ solid medium (Grosser and Gmitter, 1990a). All protoplasts were purified by passage through a $4.5 \mathrm{pm}$ stainless steel filter followed by centrifugation on a $25 \%$ sucrose-13\% mannitol gradient before mixing (Grosser and Gmitter, 1990a; Tusa et al., 1990).

Approximately equal volumes of embryogenic callus-derived protoplasts of one parent and leaf protoplasts of the second parent were mixed and fused for each parental combination (Table 1) by use of the polyethylene glycol (PEG) method of Grosser and Gmitter (1990a). Following fusion, protoplasts were cultured directly in $60 \times 15 \mathrm{~mm}$ fusion petri 

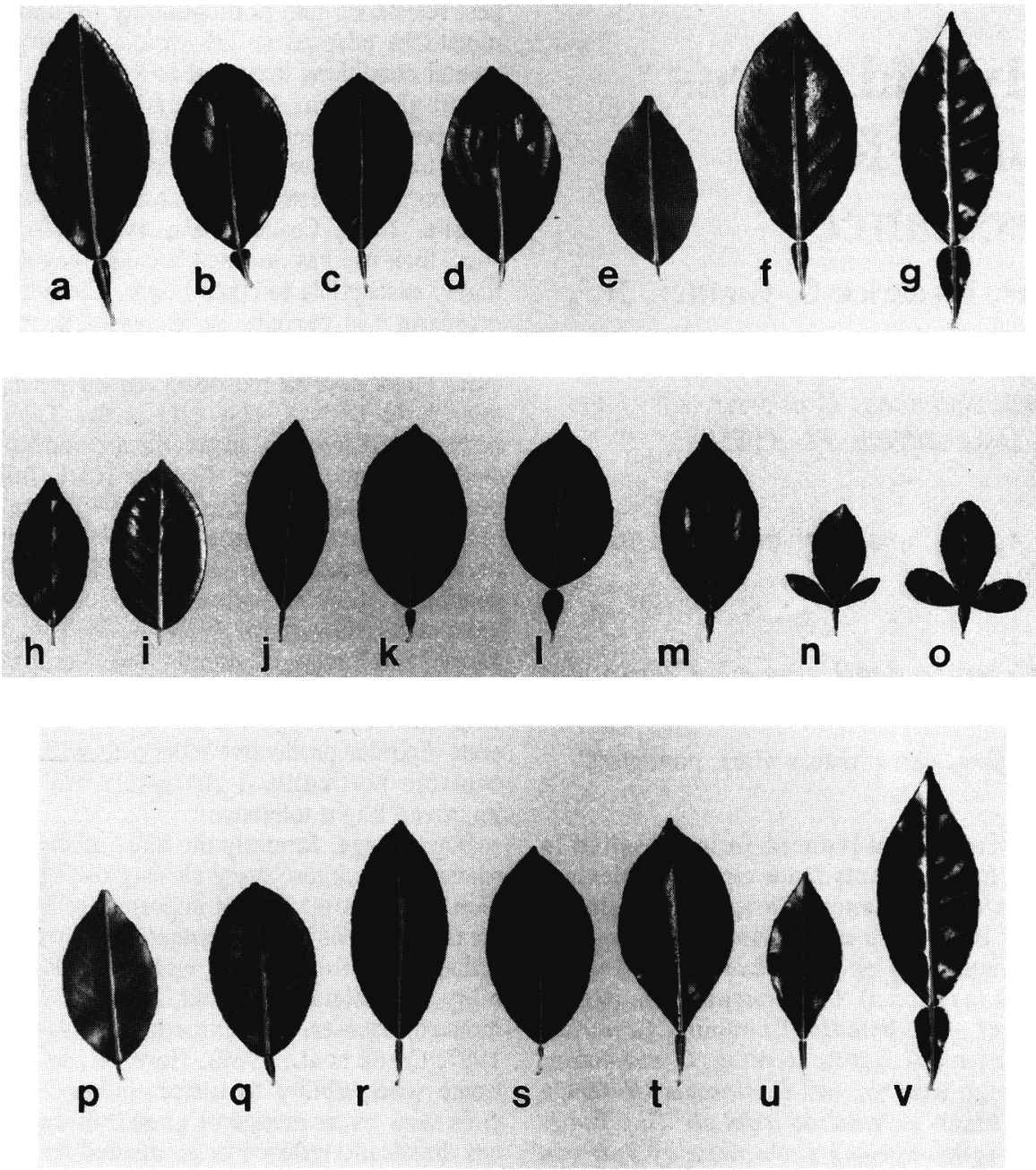

Fig. 1. Leaf morphology of: (a) Smooth Flat Seville; (b) Smooth Flat Seville + rough lemon somatic hybrid; (c) rough lemon; (d) Cleopatra mandarin + rough lemon somatic hybrid; (e, h, p) Cleopatra mandarin; (f) Cleopatra mandarin + sour orange somatic hybrid; (g, v) sour orange; (i) Cleopatra mandarin + Rangpur somatic hybrid; (j) Rangpur; (k) 'Hamlin' sweet orange + Rangpur somatic hybrid; (1) 'Hamlin' sweet orange; (m) 'Valencia' sweet orange; (n) 'Valencia' + Carrizo citrange somatic hybrid; (o) Carrizo citrange; (q) Cleopatra mandarin + Volkamer lemon somatic hybrid; (r) Volkamer lemon; (s) tetraploid Volkamer lemon zygotic; (t) sour orange + Volkamer lemon zygotic somatic hybrid (leaf type I); (u) sour orange + Volkamer lemon zygotic somatic hybrid (leaf type II).

Table 1. Summary of Citrus plant regeneration following protoplast fusion.

\begin{tabular}{|c|c|c|c|c|}
\hline \multirow[b]{2}{*}{$\begin{array}{l}\text { Embryogenic parent } \\
\text { (embryogenic callus) }\end{array}$} & \multirow[b]{2}{*}{ Leaf parent } & \multicolumn{3}{|c|}{ Plants from } \\
\hline & & $\begin{array}{c}\text { Somatic } \\
\text { hybrid }^{\mathbf{z}} \\
\text { (no.) }\end{array}$ & $\begin{array}{c}\text { Embryogenic } \\
\text { parent } \\
\text { (no.) }\end{array}$ & $\begin{array}{l}\text { Leaf parent } \\
\text { (no.) }\end{array}$ \\
\hline \multirow{4}{*}{$\begin{array}{l}\text { Cleopatra mandarin } \\
\text { (C. reticulata) }\end{array}$} & Sour orange (C. aurantium) & $171^{y}$ & 0 & 223 \\
\hline & Rough lemon (C. jambhiri) & $5^{x}$ & 0 & 0 \\
\hline & Rangpur (C. limonia) & $>1000^{x}$ & 0 & 3 \\
\hline & $\begin{array}{l}\text { Volkamer lemon } \\
\quad \text { (C. volkameriana })\end{array}$ & $8^{x}$ & 0 & 0 \\
\hline $\begin{array}{l}\text { Hamlin sweet orange } \\
\text { (C. sinensis) }\end{array}$ & Rangpur & $>1000^{\mathbf{x}, \mathrm{w}}$ & 0 & 0 \\
\hline $\begin{array}{l}\text { Valencia sweet orange } \\
\text { (C. sinensis) }\end{array}$ & Carrizo citrange & $7^{x, w}$ & 2 & 0 \\
\hline $\begin{array}{l}\text { Smooth Flat Seville } \\
\text { (C. aurantium hybrid) }\end{array}$ & Rough lemon & $3^{w}$ & & \\
\hline Sour orange (C. aurantium) & $\begin{array}{l}\text { Volkamer lemon } \\
\text { zygotic seedling }\end{array}$ & $113^{y, w}$ & 0 & $77^{\vee}$ \\
\hline
\end{tabular}

Indicates the number of plants regenerated but not necessarily the number of plants recovered from individual fusion events.

'Phosphoglucose isomerase used to confirm somatic hybridity.

'Peroxidase used to confirm somatic hybridity.

"Phosphoglucomutase used to confirm somatic hybridity.

'Includes one autotetraploid plant. dishes (Falcon, Lincoln Park, N.J.) in either EMEP protoplast culture medium (for 'Hamlin' sweet orange + Rangpur) or a 1 EMEP : $1 \mathrm{BH} 3(\mathrm{v} / \mathrm{v})$ protoplast culture media (for all remaining combinations), according to Grosser and Gmitter (1990a). Recovered somatic embryos were germinated on either $\mathrm{B}+$ embryo germination medium, DBA3 medium (Grosser and Gmitter, 1990a), or MT basal medium (Murashige and Tucker, 1969) containing (mg.liter $\left.{ }^{-1}\right)$ : 0.5 6-benzyladenine (BA), 1.0 gibberellic acid $\left(\mathrm{GA}_{3}\right)$, and 0.01 1-napthaleneacetic acid (NAA) (designated BGN).

Chromosome numbers in root-tip cells from regenerated plants were determined with the modified hematoxylin staining method of Grosser and Gmitter (1990a). Isozyme banding patterns were determined and compared with crude leaf tissue extracts of Cleopatra mandarin, 'Hamlin' and 'Valencia' sweet oranges, sour orange, Smooth Flat Seville, Carrizo citrange, rough lemon, Volkamer lemon, Rangpur, and regenerated plants. Peroxidase (PER), phosphoglucomutase (PGM), and .phosphoglucose isomerase (PGI) isozymes were separated by horizontal starch gel electrophoresis on $10 \%$ Connaught starch gels with the $\mathrm{pH} 5.7$ histidine citrate buffer of Cardy et al. (1981). Electrophoresis was carried out for $3 \mathrm{~h}$ at $4 \mathrm{C}$ and constant $60 \mathrm{~mA}$ current. Gels were stained as described by Vallejos (1983).

Plants regenerated following protoplast fusion are summarized in Table 1. The shapes of recovered somatic embryos were often abnormal, but this did not interfere with germination and plant recovery. For the 'Hamlin' sweet orange + Rangpur combination, embryo germination appeared to be most efficient on BGN medium. Embryo germination for the Cleopatra mandarin + Rangpur and sour orange + Volkamer lemon combinations appeared to be most efficient on DBA3 medium, and shoots also developed via adventitious budding on the cut surfaces of dissected embryos of these hybrid genotypes on this medium. Embryo germination for the remaining combinations was adequate on $\mathrm{B}+$ embryo germination medium. The Cleopatra mandarin + Rangpur and 'Hamlin' sweet orange + Rangpur combinations showed vigor throughout the protoplast to plant cycle, as demonstrated by the large populations of hybrid plants recovered (Table 1). The Cleopatra mandarin and sour orange callus lines apparently lost their regeneration capability, because no plants were regenerated from nonfused protoplasts of these lines. Plant regeneration of 'Hamlin' sweet orange from nonfused callus-derived protoplasts was inhibited by the high-sucrose content of EMEP protoplast culture medium, as previously reported (Grosser et al., 1988a, 1988b; Ohgawara et al., 1985). Numerous diploid plants of sour orange, the zygotic Volkamer lemon, and a few plants of Rangpur were regenerated from nonfused leaf protoplasts. A tetraploid plant of the zygotic Volkamer lemon was also recovered, apparently resulting from a homokaryotic fusion. These results probably depended on co-culture with embry- 
Table 2. Designated leaf isozyme genotypes of the donor Citrus parents for peroxidase (PER), phosphoglucose isomerase (PGI), and phosphoglucose mutase (PGM).

\begin{tabular}{lccr}
\hline \hline Donor & PER & PGI & PGM \\
\hline Cleopatra mandarin & FF & MM & FF \\
Sour orange & FS & WS & FS \\
Rough lemon & SS & MS & FI \\
Volkamer lemon & SS & MS & FI \\
Volkamer lemon zygotic & SS & MS & IS \\
Rangpur & SS & MS \\
Hamlin/Valencia orange & FF & MS & FI \\
Smooth Flat Seville & FS & MS & FS \\
Carrizo citrange & FP & SS & FS \\
\hline
\end{tabular}

ogenic culture-derived protoplasts and add to the growing number of genotypes amenable to plant regeneration from leaf protoplasts (Grosser et al., 1991; Ohgawara et al., 1989; Tusa et al., 1990).

The leaf morphology of all recovered somatic hybrid plants was intermediate to that of the parents (Fig. 1). Two distinct morphological types were unexpectedly observed in the population of sour orange + Volkamer lemon zygotic somatic hybrid plants (designated types I and II) (Fig. 1), with about three times as many type I as type II plants. Both types exhibited the same isozyme banding patterns for PER, PGI, and PGM. This is the first time we have observed morphological variation in somatic hybrid plants from a single parental combination. This variation may be explained by differences in the inheritance of chloroplast and/or chondriome genomes in the two types. Kobayashi et al. (1991) showed differential inheritance of chloroplast genomes in somatic hybrid plants of nave1 orange ( $C$. sinensis) and 'Murcott' tangor, but no morphological variation was observed.

Chromosome number determinations confirmed tetraploidy $(2 \mathrm{n}=4 \mathrm{x}=36)$ for all eight somatic hybrid combinations, Leaf isozyme genotypes (PER, PGI, PGM) for all donors are listed in Table 2. Expression of all parental alleles (complementation) was observed in the putative somatic hybrids (with one exception described below) and confirmed their hybridity. For the monomers (PER, PGM), complementation was observed simply as additive expression of parental bands; for PGI (a dimeric enzyme), complementation resulted in the appearance of all parental bands plus unique heterodimers not present in either parent. The enzyme activity staining systems diagnostic of hybridity for each combination are noted in Table 2.

Isozyme analysis indicated that the Volkamer lemon seedling that provided the leaf protoplasts used in the fusions with sour orange was of zygotic origin. This original Volkamer lemon seedling and plants regenerated from nonfused leaf protoplasts of this plant displayed an IS isozyme banding pattern at the PGM locus, whereas true-to-type Volkamer lemon is FI. The zygotic Volkamer lemon plants displayed the typical Volkamer lemon patterns for the PER and PGI loci (Table 2). The isozyme banding pattern of the sour orange + Volkamer lemon zygotic somatic hybrid plants for PGM was FI and did not show the $\mathrm{S}$ allele that we expected to be contributed by both parents. The $S$ allele was either lost or its expression blocked in these plants for reasons we cannot explain. All sour orange + Volkamer lemon zygotic somatic hybrid plants were clearly hybrid at the PGI locus, showing the expected WMSS banding pattern. We have previously observed and explained missing isozyme bands in somatic hybrid plants on two occasions. An expected M band at the PGI locus was not present in Milam lemon (Citrus jambhiri Lush purported hybrid) + 'Femminello' lemon ( C. limon L. Burm. F.) somatic hybrid plants, but the $\mathrm{M}$ band was also missing in the parental Milam lemon callus line and plants regenerated from this line (Tusa et al., 1992). An expected S band at the PGI locus was not present in 'Hamlin' sweet orange ( $C$. sinensis) + Severinia buxifolia Poir. Tenore, but these plants were also missing chromosomes $(2 \mathrm{n}=27$, whereas the expected chromosome number was $2 \mathrm{n}=$ $4 \mathrm{x}=36$ )

Plants of the somatic hybrid rootstocks reported herein have been propagated and entered into field trials. Determining their characteristics and the nature of the genetic control of important traits should provide a valuable basis for selecting parents for future somatic hybridizations.

\section{Literature Cited}

Cardy, B.J., C.W. Stuber, and M.M. Goodman. 1981. Techniques for starch gel electrophoresis of enzymes for maize ( Zea maize L.). Inst. Statistics Mimeogr. Series 1317. North Carolina State Univ., Raleigh.

Castle, W.S. 1987. Citrus rootstocks, p. 361-399. In: R.C. Rom and R.F. Carlson (eds.). Rootstocks for fruit crops. Wiley, New York.

Castle, W.S., D.P.H. Tucker, A.H. Krezdom, and C.O. Youtsey. 1989. Rootstocks for Florida citrus. Univ. of Florida, Coop. Ext. Publ. SP 41.

Deng, X.X., J.W. Grosser, and F.G. Gmitter, Jr. 1991. Intergeneric somatic hybrid plants from protoplast fusion of Fortunella crassifolia 'Meiwa' with Citrus sinensis 'Valencia'. Scientia Hort. 49:55-62.

Grosser, J.W. 1991. In vitro methods for tropical fruit improvement. In: I.K. Vasil and T.A. Thorpe teds.). Plant tissue culture: Theory and applications. Kluwer Academic Publishers, Dordrecht, The Netherlands. (In Press.)

Grosser, J.W. and J.L. Chandler. 1987. 'Aseptic isolation of leaf protoplasts from Citrus, Poncirus, Citrus $\times$ Poncim hybrids and Severinia for use in somatic hybridization experiments. Scientia Hort. 31:253-257.

Grosser, J.W. and F.G. Gmitter, Jr. 1990a. Pro- toplast fusion and Citrus improvement. Plant Breeding Rev. 8:339-374.

Grosser, J.W. and F.G. Gmitter, Jr. 1990b. Wide hybridization of Citrus via protoplast fusion: Progress, strategies and limitations, p. 31-41. In: A.B. Bennett and S.D. O'Neill (eds.). Horticultural biotechnology, Plant biology. vol. 25. Wiley-Liss, New York,

Grosser, J.W. and F.G. Gmitter, Jr. 1990c. Somatic hybridization of Citrus with wild relatives for germplasm enhancement and cultivar development. HortScience 25:147-151.

Grosser, J.W., F.G. Gmitter, Jr., and J.L. Chandler. 1988a. Intergeneric somatic hybrid plants of Citrus sinensis cv. Hamlin and Poncirus trifoliata cv. Flying Dragon. Plant Cell Rpt. 7:58.

Grosser, J.W., F.G. Gmitter, Jr., and J.L. Chandler. 1988b. Intergeneric somatic hybrid plants from sexually incompatible woody species: Citrus sinensis and Severinia disticha. Theor. Applied Genet. 75:397-401.

Grosser, J.W., F.G. Gmitter, Jr., F. Sesto, X.X Deng, and J.L. Chandler. 1991. Six new somatic citrus hybrids and their potential for cultivar improvement. J. Amer. Soc. Hort. Sci. 117:169-173.

Grosser, J,W., F.G. Gmitter, Jr., N. Tusa, and J.L. Chandler. 1990. Somatic hybrid plants from sexually incompatible woody species: Citrus reticulata and Citropsis gilletiana. Plant Cell Rpt. 8:656-659.

Grosser, J.W., G.A. Moore, and F.G. Gmitter, Jr. 1989. Interspecific somatic hybrid plants from the fusion of 'Key' lime (Citrus aurantifolia) with 'Valencia' sweet orange (Citrus sinensis) protoplasts. Scientia Hort. 39:23-29.

Kobayashi, S., K. Fujiwara, I. Oiyama, T. Ohgawara, and S. Ishii. 1988a. Somatic hybridization between navel orange and 'Murcott' tangor. 1988 Proc. Intl. Soc. Citriculture 1:135-140.

Kobayashi, S., T. Ohgawara, K. Fujiwara, and I. Oiyama. 1991. Analysis of cytoplasmic genomes in somatic hybrids between navel orange (Citrus sinensis Osb.) and 'Murcott' tangor. Theor. Applied Genet. 82:6-10.

Kobayashi, S., T. Ohgawara, I. Oiyama, and S. Ishii. 1988b. A somatic hybrid plant obtained by protoplast fusion between navel orange (Citrus sinensis) and satsuma mandarin (Citrus unshiu). Plant Cell, Tissue \& Organ Cult. 14:63 69.

Murashige, T. and D.P.H. Tucker. 1969. Growth factor requirements of Citrus tissue culture. Proc. First Intl. Citrus Symp. 3:1155-1161.

Ohgawara, T., S. Kobayashi, S. Ishii, K. Yoshinoga, and I. Oiyama. 1989. Somatic hybridization in Citrus: Navel orange ( C. sinensis Osb.) and grapefruit ( $C$. paradisi Macf.). Theor. Ap: plied Genet. 78:609-612.

Ohgawara, T., S. Kobayashi, E. Ohgawara, H. Uchimiya, and S. Ishii. 1985. Somatic hybrid plants obtained by protoplast fusion between Citrus sinensis and Poncirus trifoliata. Theor. Applied Genet. 71:14

Tusa, N., J.W. Grosser, and F.G. Gmitter, Jr. 1990. Plant regeneration of 'Valencia' sweet orange, 'Femminello' lemon, and the interspecific somatic hybrid following protoplast fusion. J. Amer. Soc. Hort. Sci. 115:1043-1046.

Tusa, N., J.W. Grosser, F.G. Gmitter, Jr., and E.S. Louzada. 1992. Production of tetraoloid somatic hybrid breeding parents for use in lemon cultivar improvement. HortScience 27:445-447.

Vallejos, C.E. 1983. Enzyme staining activity, p. 469-516. In: S.D. Tanksley and T.J. Orton (eds.). Isozymes in plant genetic and breeding, part A. Elsevier, Amsterdam.

Vardi, A., P. Arzee-Gonen, A. Frydman-Shani, S. Breichman, and E. Galun. 1989. Protoplast- 
fusion-mediated transfer of organelles from $\mathrm{Mi}$ crocitrus into Citrus and regeneration of novel alloplasmic trees. Theor. Applied Genet. 78:741747.

Vardi, A., A. Breiman, and E. Galun. 1987. Cit- rus cybrids: Production by donor-recipient protoplast-fusion and verification by mitochondrial-

DNA restriction profiles. Theor. Applied Genet. 75:.51-58

Vardi, A. and E. Galun. 1988. Recent advances in protoplast culture of horticultural crops. Scientia Hort. 37:217-230.

Whiteside, J.O., SM. Garnsey, and L.W. Timmer (eds.). 1988. Compendium of citrus diseases. APS Press, St. Paul. 